\title{
DO HONEYBEES ACT AS POLLEN THIEVES OR POLLINATORS OF DATURA
}

\section{WRIGHTII?}

\author{
Andrew C. McCall*,1, Sarah Richman²,3, Eric Thomson"1, Monica Edgerton¹, Skyler Jordan¹, Judith L. \\ Bronstein ${ }^{2}$
}

${ }^{1}$ Department of Biology, Denison University, Granville OH 43023 USA

${ }^{2}$ Department of Ecology and Evolutionary Biology, University of Arizona, Tucson AZ 85721 USA

${ }^{3}$ Present address: Department of Biology, University of Nevada, Reno; Reno NV 89557 USA

\begin{abstract}
Datura wrightii (Solanaceae), a common shrub in the southwestern United States, bears massive, white, night-blooming flowers that attract and reward hawkmoth pollinators. However, Apis mellifera (honeybee) foragers are often observed on its flowers, especially at dusk and dawn hours. Their foraging activities are focused on the anthers, suggesting they could be pollen thieves. We used a series of observations and manipulative experiments to determine if honeybees are detrimental or beneficial to $D$. wrightii. We found that honeybees were the most frequent visitors to $D$. wrightii flowers at both dusk and dawn, and that they removed and carried large amounts of $D$. wrightii pollen. Flowers were capable of being pollinated at dusk and dawn and a single visit by a honeybee was sufficient to pollinate the flowers and produce fruit. There was no evidence that restricting visitation to diurnal hours yielded fruit set that was different from when we restricted visitation (likely by hawkmoths) to evening hours. These results suggest that honeybees are capable of effective pollination of $D$. wrightii. Although honeybees might interfere with pollen transmission mediated by their highly specialized hawkmoth pollinators, they may also increase plant fitness by pollinating D. wrightii when hawkmoths are not present.
\end{abstract}

Keywords: Pollen theft, pollen thieves, Datura wrightii, Apis mellifera

\section{INTRODUCTION}

Floral tissue can be damaged by animals in a number of ways. For example, it may be consumed (florivory; McCall \& Irwin 2006), or may be damaged by foragers that then feed upon nectar without concomitant pollination (nectar robbery; sensu Inouye 1980; Irwin et al. 2010). In pollen theft, as defined by Hargreaves et al. (2009) and Solís-Montero et al. (20I5), thieves are visitors that can consume pollen without causing significant cross-pollination. Although florivory and nectar robbery have received recent attention in the literature (see Irwin et al. 2010 and González-Browne et al. 2016 for reviews), there are fewer studies that consider the effect of pollen thieves on plant reproductive success (Hargreaves et al. 2009).

Pollen theft is a product of interactions between the potential thief and the host plant's floral structure and development. For example, if there are temporal differences between the timing of pollen presentation and stigma receptivity (dichogamy), then a potential thief could consume pollen and have pollen present on its body without effecting pollination (Hargreaves et al. 2009; Hargreaves et al. 2012). Vaughton (1996) found that pollen-collecting A. mellifera (honeybees) visited male-phase Grevillea barklyana

Received 2I July 20I8, accepted I8 October 2018

*Corresponding author: mccalla@denison.edu
(Proteaceae) but seldom visited female-phase flowers. This habitual theft reduced plant fitness, as flowers caged to allow only honeybee visits set fewer fruit than bagged control flowers. Pronounced spatial separation of anthers and stigmas (herkogamy) in flowers could also contribute to theft because a visitor may not be able to transfer pollen to stigmas if the distance between the reproductive organs is too great (Hargreaves et al. 2009; Solís-Montero et al. 2015).

Pollen theft may be more prevalent in plants with specialized flowers than in plants with more generalized flowers because unique floral structures could preclude efficient pollination by generalist floral visitors (Aslan et al 2016). Visitors such as honeybees may act as pollen thieves because they are frequent visitors to many flowers but are often inefficient in transferring pollen to stigmas or do not demonstrate the specific behavior needed for pollen release. For example, only $18 \%$ of honeybee visits to the buzzpollinated Solanum rostratum resulted in contact to both an anther and the stigma, even though honeybees made up $95.8 \%$ of total insect visits (Solís-Montero et al. 2015). In Syncolostemon densiflorus (Lamiaceae), a plant with a birdpollinated flower, Wester and Johnson (2017) found that honeybee foragers were frequent floral visitors but they did not pollinate effectively, most likely because foragers did not contact the stigmas.

The perennial herb Datura wrightii (Solanaceae) would appear to be particularly susceptible to pollen theft because honeybees frequent collect only pollen (Fig. IA, A. McCall, pers. obs.), and flower exhibit pronounced herkogamy, 

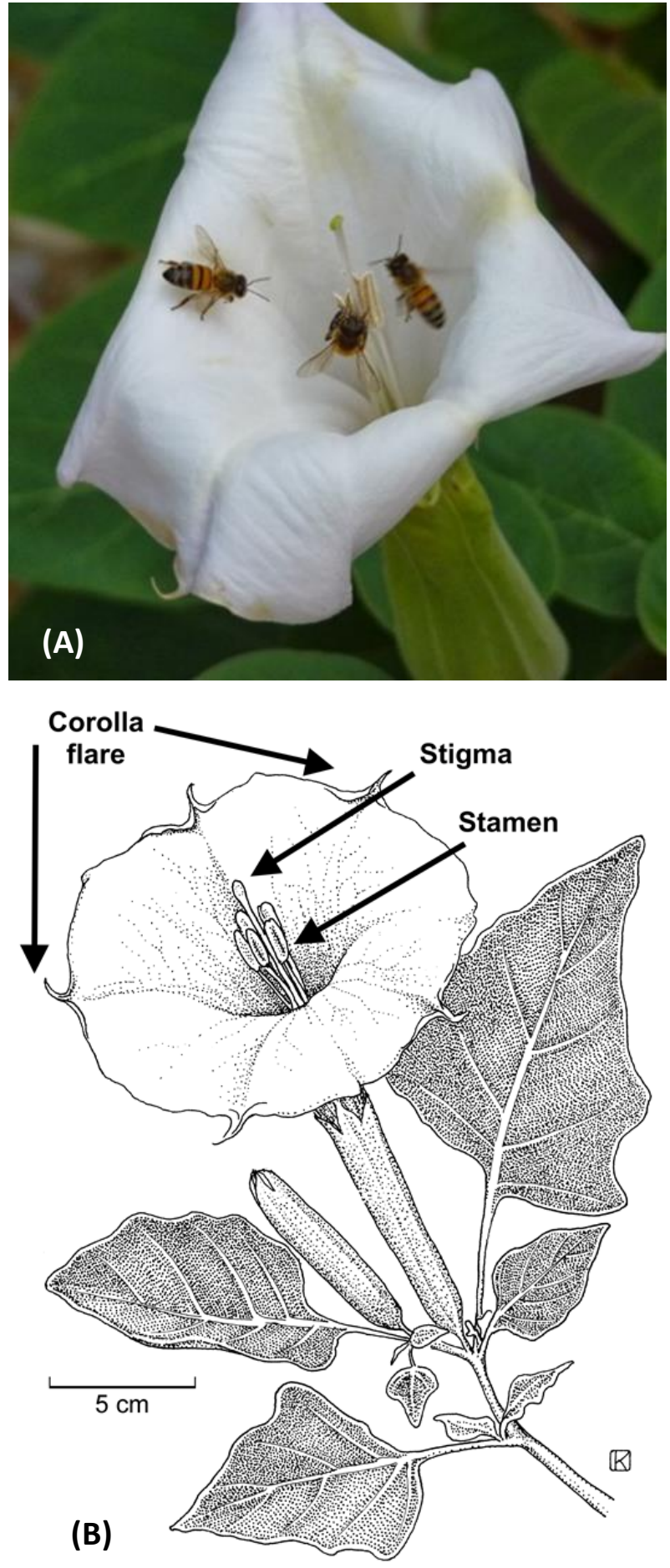

FIGURE I. (A) Photo of honeybees entering the corolla headspace and collecting pollen from anthers. Photo used with permission from Deborah Wilson. (B) Line drawing of D. wrightii flowers and habit. Stamens, the exerted stigma and the corolla flare are labeled. Drawing reprinted with permission from the Jepson Herbarium, UC Berkeley.

sometimes precluding contact of the stigma by the foragers (Fig. IB, Bronstein et al. 2009). The main pollinators in this system are hawkmoths, in southern Arizona most notably Manduca sexta (Sphingidae), which also lays its eggs on the plants whose flowers it visits (Bronstein et al. 2009). However, flowers are also visited at dusk and dawn by honeybees (Apis mellifera (Apidae)), introduced species in Arizona that appear to collect large amounts of pollen without contacting stigmas (A. McCall, pers. obs.). This would suggest that honeybees might remove pollen without providing efficient pollen transfer in the process. Furthermore, because hawkmoths are most active at night, when honeybees do not fly, pollen collection by honeybees at dusk could reduce the amount of pollen available for more effective pollinators. This is possible because individual $D$. wrightii flowers are typically only open in a single interval, from dusk until dawn in a 24hour period. Alternatively, honeybee visitation during dawn hours could add pollen deposition and removal beyond that caused by hawkmoth activity (Barker and Bronstein 2016).

We examined whether honeybees might act as conditional pollen thieves of $D$. wrightii. Our first set of questions focus on the specific attributes of honeybees or $D$. wrightii that might promote conditional pollen theft: I) Do honeybee foragers visit $D$. wrightii flowers before hawkmoths visit, and do they contact anthers and stigmas during these visits? 2) Do honeybee foragers remove pollen from $D$. wrightii anthers? and 3 ) Do honeybee foragers carry pollen on their bodies? We then consider honeybee attributes that might contribute to their ability to serve as pollinators: I) Are D. wrightii flowers able to set fruit when hand-pollinated during dawn hours, just before the single-night flowers close and senesce, mimicking the actions of dawn-foraging bees? 2) Is a single visit from a honeybee forager sufficient to set fruit? Finally, 3) Are flowers exposed to honeybees able to set fruit at the same rate as those flowers exposed to either nocturnal, presumably pollinating moths or control flowers open to all visitors? If honeybees cause lower rates of fruit set than moths, then there would be evidence that they are conditional pollen thieves. Alternatively, if fruit set is similar when flowers are exposed to honeybees or exposed to moths, then there would be evidence that honeybees are legitimate pollinators within this hawkmoth pollination system.

\section{MATERIALS AND METHODS}

\section{Study system}

Datura wrightii (Solanaceae) is a perennial herb found from Western Texas to California and Mexico (Kearney \& Peebles 1960). Flowering occurs from mid-April to early November. Flowers are large (maximum length is $\sim 25 \mathrm{~cm}$ ), white, and tubular. The flowers open at dusk and remain open for a single night, although flowers can remain turgid in the morning hours if the temperatures are cool (A. McCall, personal observation). Flowers frequently exhibit pronounced herkogamy, with anthers positioned over the stigmas (see Fig. IA and B, Bronstein et al. 2009), which may preclude selfpollination by pollinators. Flowers are self-compatible and frequently set fruit without pollinator activity (Bronstein et al. 2009). Manduca sexta individuals forage exclusively nocturnally and are highly effective pollinators at this site (Bronstein et al. 2009); the same is likely true of the rarer congener M. quinquemaculata (Alarcón et al. 2010).

Previous observations revealed that honeybee foragers frequently visit $D$. wrightii flowering buds, especially anthers, even before floral anthesis and nightfall (A. McCall, pers. 
obs.). These foragers often land on the large floral buds and will sometimes force their way into the bud to collect pollen. These activities can occur 2-3 hours before $M$. sexta visits the fully-opened flowers, allowing honeybees to remove pollen before M. sexta arrives (A. McCall, pers. obs.). Although we observed several species of native bees visiting $D$. wrightii flowers, some of which are small enough to collect pollen from anthers without contacting stigmas (Thorp 2000), we chose to focus on honeybees because they are usually the most abundant floral visitor at dusk in the $D$. wrightii populations we examined. We also observed frequent honeybee visitation at dawn, before flowers wilted due to heat.

\section{Sites}

Most of this study was conducted at the University of Arizona Campus Agricultural Center in Tucson, Arizona (the "Farm population", N 32.280, W I I0.938). Datura wrightii seeds were collected in 2007 from a wild population at the Santa Rita Experimental Range (SRER, N 3I.788, W I I0.828). In 2008 these seeds were planted at the Agricultural Center. They were grown under field conditions with occasional watering. In late 2008 we collected fruit from these plants and massed their seed to produce the seed source for our experimental plot. In 2009, we planted 96 seeds in each of two adjacent tilled and cleared blocks. Blocks were occasionally watered and weeded but were otherwise unmanipulated. The second site was a natural population of D. wrightii located along Box Canyon Road (the "Box Canyon" population, N 3I.775, W II0.7I5) in the Santa Rita Mountains, adjacent to the Santa Rita Experimental Range.

\section{Pollinator surveys}

In order to quantify floral visitation to $D$. wrightii, we observed visitor behavior at the Box Canyon population. Beginning on II July 20 I I and over a period of one week, we observed floral visitors on as many flowering plants as possible. Our observations took place as the flowers were opening, at approximately 1900h. A 'visit' was defined as taking place when an insect broke the plane of the corolla flare into the headspace of the flower (see Fig. IB). We observed an insect visitor until it left the corolla or until five minutes had elapsed. Because there were often numerous insects approaching many flowers on a plant, we focused on a single flower and a single individual insect for each replicate. We described the insect's behaviors using the following mutuallyexclusive categories: gathering pollen on anthers, contacting the stigma, contacting both the stigma and anthers, or not contacting any primary reproductive structures. A total of 228 individual visitors of ten different species were observed.

\section{Pollen removal experiments}

Honeybee foragers might be more prevalent during dawn versus dusk hours because they are primarily diurnal insects, possibly leading to more pollen removed in the morning. To determine if honeybee foragers removed different pollen amounts at different times of the day, we conducted an experiment at the Farm population on I8 Sept, 27 Sept and 4 Oct 2012. On each day, we identified all plants with nearlyopen floral buds and haphazardly chose 60 of them to be bagged with bridal veil. We then randomly assigned buds to one of three treatments: I) Controls with no visitation, 2) Honeybee visitation at dusk only, and 3) Honeybee visitation at dawn only. For each of the treatment flowers, we collected and weighed anthers as a proxy for pollen mass. In order to move the anthers from flowers to collection envelopes without spilling pollen, it was necessary to include a small portion of the filaments for all treatments.

We removed the bags from 20 flowers at approximately I900h, prior to hawkmoth activity. For the dawn treatment, we removed bags from 20 flowers at $0500 \mathrm{~h}$ and allowed bees to visit for the same length of time as in the dusk treatment ( $\mathrm{I} .5 \mathrm{hr}$ ), then removed anthers. As a control, we collected five anthers from each of 20 bagged, unvisited flowers. Collected anthers were placed in glassine envelopes (I envelope/flower). Anther samples were dried for I week at $60^{\circ} \mathrm{C}$ and then weighed.

We constructed a linear mixed model with weight of anthers per flower as the dependent variable, treatment (control, dusk, or dawn) as the fixed independent variable and day and day by treatment interactions as the random independent effects. The model was constructed using the 'Imer' function in the R package 'lme 4' (v. I.I-6; Bates et al. 20I5). The effect of the treatment was determined by constructing another linear mixed model identical to the first, except without the treatment effect. The two models were then tested against each other using log likelihood ratio tests implemented by the 'Anova' function in the R package 'car' (Fox \& Weisberg 20II). If the overall treatment effect was significant, we performed pairwise Wald tests to determine which treatment levels were significantly different from each other.

\section{Examination of honeybees and pollen}

To determine if honeybees carry pollen in their corbicula, at I800h on I3 July 20 I I we collected II honeybee foragers on D. wrightii flowers from the Farm population. We removed pollen from the corbicula of each bee and examined it under a dissecting microscope. We compared these samples to reference slides of $D$. wrightii pollen to determine whether each pollen load included $D$. wrightii pollen. We did not identify pollen grains other than $D$. wrightii. There was a small possibility that pollen grains from the congener $D$. discolor were also present, but the two types of pollen are quite distinct and can easily be differentiated under a microscope (G. Smith, personal communication).

\section{Dusk versus Dawn pollination}

Honeybees could visit flowers at dusk or dawn, but stigmas may not be competent to receive pollen in the morning, as flowers are usually only open one night. To test if $D$. wrightii flowers have the capability to set fruit when pollinated at dusk or dawn, we conducted an experiment on all plants in the Farm population. From I7-29 July 2013 we haphazardly chose an open flower on a given plant as the pollen donor for both evening and morning-pollinated flowers on that plant. We did this to mimic within-plant visitation on plants bearing more than one flower, which is often observed on larger plants when honeybees are foraging 
at dusk. On each evening of the experiment, we bagged floral buds that were about to open. As they opened, each flower was randomly assigned to either a 'dusk' or 'dawn' pollination treatment. For dusk-pollinated flowers, we removed the bag and brushed two anthers from the donor flower across the stigma five times at anthesis, after which the bag was closed. Dawn-pollinated flowers were allowed to open inside their bags in the evening and remained bagged until approximately 0500 the following morning, just as honeybee activity began and after M. sexta activity ceased. We then took two of the remaining anthers from the open donor flower and brushed them across the flower's stigma five times. The flower was then rebagged to prevent honeybee foragers from adding additional pollen to the flower. It is important to note that, for the dawn-pollinated plants, we used pollen from the donor flower that had been collected the previous evening. We did this to ensure that we would have sufficient pollen available to deposit similar amounts of pollen at both time periods.

Both dusk and dawn-pollinated flowers were bagged for two days until fully wilted. In total, I 5 flowers were pollinated at dawn and 23 at dusk. Fruit set was recorded on 3I Aug and 3 Sept 2013. We analyzed the data using a generalized linear mixed model (GLMM) with fruit presence or absence as the response variable, pollination time treatment as a fixed variable, plant as a random variable, and a binomial error structure. The model was implemented using the glmet function under the Ime4 package in R. An identical model but without the treatment effect was constructed, and the two models were tested against each other using log likelihood ratio tests.

\section{Single bee visits}

To determine if honeybees can act as pollinators, we conducted an experiment to measure the effect of a single visit. On 2 July 2012 and ending 2 Aug 20I2, we randomly assigned floral buds in the Farm population to experimental treatments. We visited the site every other day at midday and used those plants that were flowering on each day to supply the buds for treatments. In treatment I, we bagged flowers, then rolled down the top of the bag at dusk (approximately I9I5h) to allow all pollinators access to the flower until evening (2030h), when the bags were closed. In treatment 2, buds were allowed to reach anthesis inside the bags. Bags were then removed at dusk to allow a single honeybee to enter and contact the reproductive organs of each flower. After a single visit, the bags were immediately closed. Finally, the control treatment consisted of buds that were allowed to open in the bag but were never exposed to pollinators. All bags remained on the flowers until midday on the following day, when the flowers began to wilt. Our procedure yielded a total of 69 closed control flowers, 24 open-pollinated flowers, and 4I flowers visited by a single bee. Fruit set was recorded on 6 and IO Aug 2012 and again on I2 Nov 2012.

Data were analyzed using a GLMM with fruit presence or absence as the response variable and Julian date of anthesis, plant (random effect), and treatment as the independent variables. We used a binomial error structure in the model. We constructed a full model with the treatment factor and a reduced model without the treatment factor and these models were tested against each other using log likelihood ratio tests.
If the overall treatment effect was significant, we performed pairwise Wald tests to determine which treatment levels were significantly different from each other.

\section{Pollinator exclusion}

We investigated whether floral visitors active at different times differed in their ability to pollinate $D$. wrightii. We first exposed individual flowers to visitors during diurnal, nocturnal, and crepuscular periods at the Farm population from 5 July to I4 Aug 20I0. As plants came into flower, each flower was randomly assigned to one of five treatments: a bridal veil bag opened from anthesis until dawn (07:30) $(N$ $=25)$, a bag left on to permit self-pollination only $(\mathrm{n}=30)$, a bag open only from 19:00 to 20:30 (dusk, $N=29$ ), a bag open from 20:30 until 04:30 (night, $N=28$ ), and a bag open from 04:30 until 07:30 (dawn, $N=25$ ). Not all treatments were applied on the same day because plants often had fewer than five flowers open on a single night. After two days, bags were removed from all flowers and the flowers, now fully wilted, were tagged. Fruit set was recorded on I5 Aug 2010.

We analyzed the data using a GLMM with presence of fruit as the dependent variable and time treatment (fixed), plant (random), and Julian date of manipulation (continuous covariate) as independent variables. We specified a binomial error structure and implemented the analysis using the glmer function under the Ime 4 package in R. An identical model but without the treatment effect was constructed in the same way, and we tested the two models against each other using log likelihood ratio tests in $\mathrm{R}$.

Unless otherwise noted, all analyses were performed using R (R Core Team, 20I4, v. 3.0I, "Good Sport").

\section{RESULTS}

\section{Pollinator surveys}

We identified the following visitor species to Datura wrightii flowers: honeybees (Apis mellifera), two beetle species (Cyclocephala melanocephala and an unidentified species (Scarabaeidae)), three hawkmoth species (Hyles lineata, Manduca sexta and an unidentified species (Sphingidae)), and several unidentified species of ants, wasps, and flies. The four most common visitors, making up 91.2\% of all visits, were honeybees (I43 visits), Manduca sexta (I4 visits), Cyclocephala melanocephela (I0 visits), and the unidentified scarab beetle (33 visits).

The proportion of visits in which the visitor contacted the primary reproductive tissue varied among the visitors, with honeybees and $M$. sexta contacting these tissues in the highest proportion of visits (Table I)

\section{Pollen removal and pollen on honeybees}

We conducted this experiment to find if honeybees removed pollen and if the amount of pollen removed depended on the time of day. Whether plants were exposed to honeybee visits at dusk only, at dawn only, or were unvisited affected the mass of pollen in the anthers $\left(\chi^{2}=74.06,2 \mathrm{df}, P\right.$ $<0.000$ I, Fig. 2). Pollen mass in dawn-visited anthers was significantly less than in closed control anthers and pollen mass in dusk-visited anthers was less than in control flowers. 
TABLE I. The number of individual insects contacting reproductive organs among the four most common floral visitors to D. wrightii. Categories are mutually exclusive. Also shown is the percent of visits resulting in contact with any reproductive organs for each visitor.

\begin{tabular}{lcccccc}
\hline Visitor & Anther & Stigma & $\begin{array}{c}\text { Stigma and } \\
\text { anther }\end{array}$ & $\begin{array}{c}\text { No reproductive } \\
\text { organs }\end{array}$ & $\begin{array}{c}\text { \% visits contacting } \\
\text { any reproductive organ }\end{array}$ & Total visits \\
\hline A. mellifera & 29 & I & 32 & 82 & 42.67 & I \\
C. melanocephala & 0 & 0 & 0 & 10 & 0 & 10 \\
M. sexta & 0 & 0 & II & 3 & 78.57 & I \\
Unidentified scarab & I & 2 & I & 29 & 12.12 & 33 \\
\hline
\end{tabular}

We also found that anthers visited at dawn had significantly lower pollen masses than anthers visited at dusk, suggesting that dawn visits removed more pollen than dusk visit did. All honeybee foragers were carrying $D$. wrightii pollen.

\section{Dusk and dawn pollination}

In this experiment, we tested if there was a difference in pollination efficacy between dusk and dawn hours. The model with the time of pollination effect explained significantly more of the deviance than the model without the time of pollination effect (With treatment AIC $=50.3$, Without treatment AIC $=54.0, \chi^{2}=5.73$, I df, $\left.P=0.017\right)$. In particular, there was a significant difference in the proportion of flowers setting fruit between the dawn and dusk treatments (Dusk pollination $=$ $78.3 \%$, Dawn pollination $=21.7 \%, z=2.3 \mathrm{I}, P=0.02 \mathrm{I})$.

\section{Single bee visits}

We tested if flowers receiving a single honeybee forager visit set fruit at a different rate than flowers without a visit (i.e., that only had the opportunity for self-pollination) or

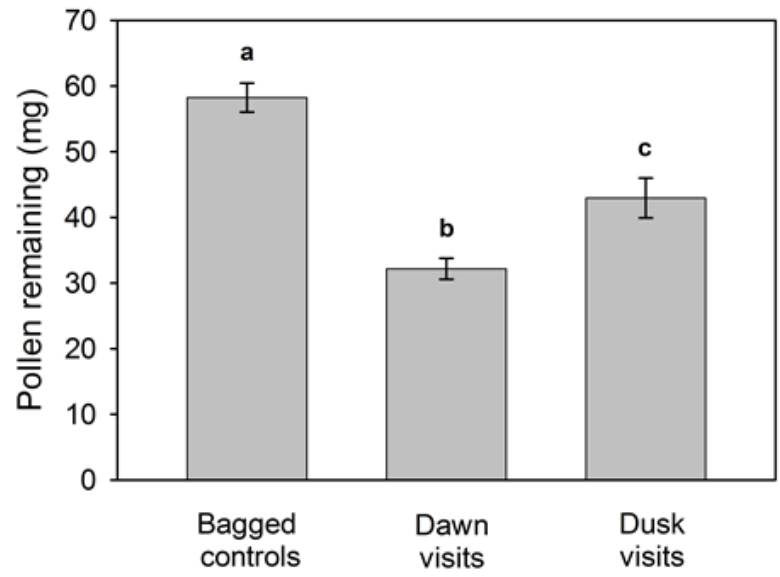

Honeybee visitation treatment

FIGURE 2. Mass of pollen remaining in unvisited control flowers, flowers open to pollinators at dawn only, and flowers open to pollinators at dusk only. Lines represent means and +/- I SE. Letters indicate percentages that are significantly different from each other at the $P=0.05$ level. flowers open to all pollinators. There was a significant effect of pollination treatment on fruit set (With treatment AIC = I36.02, Without treatment AIC $=139.36, \chi^{2}=7.34,2 \mathrm{df}, P$ $=0.025)$. Among the treatments, there were significant differences in the proportion of flowers setting fruit between the closed control and bee treatments $(z=2.329 P=0.02)$ and between the control and the open pollination treatments $(z=2.080, P=0.037$ ), but no evidence of a difference between the bee and open pollination treatments $(z=0.24 \mathrm{I}$, $P=0.809$, Fig. 3).

\section{Pollinator exclusion}

To determine if pollinator activity at different times of day affected fruit set, we exposed open flowers during dusk, nighttime, and dawn hours to potential pollinators. There were no significant differences between the model with the experimental treatment effect and model without the experimental treatment effect $\left(\chi^{2}=0.17,4 \mathrm{df}, P=0.99\right.$, percent flowers setting fruit in closed controls $=13.3 \%$, open controls $=4.0 \%$, open at dusk $=17.9 \%$, open at night $=$ $21.4 \%$, open at dawn $=20.0 \%$, Fig. 4 ).

\section{DISCUSSION}

Pollen theft is an understudied plant-insect interaction, particularly from the perspective of its effect on plant fitness (Hargreaves et al. 2009). The purpose of this study was to investigate if honeybee foragers are conditional pollen thieves or pollinators of Datura wrightii. It appears that honeybees are not conditional thieves because they are able to effect pollination. Honeybees were frequent dusk visitors to $D$. wrightii. We show here that foragers collect pollen during their visits, and that large amounts of $D$. wrightii pollen can be found on their corbicula. A single honeybee visit significantly increased the proportion of flowers setting fruit compared to unvisited flowers. The percentage of flowers setting fruit during diurnal or dusk/dawn periods, when honeybees are common visitors, did not differ significantly from the percentage of flowers setting fruit during nocturnal periods, when hawkmoths, their specialist pollinators, are most active.

In the last experiment mentioned, it is important to note that the quality or quantity of the seeds from fruit may have differed depending on the bagging treatment. Seed quality may depend on whether seeds come from autogamous selfing, 


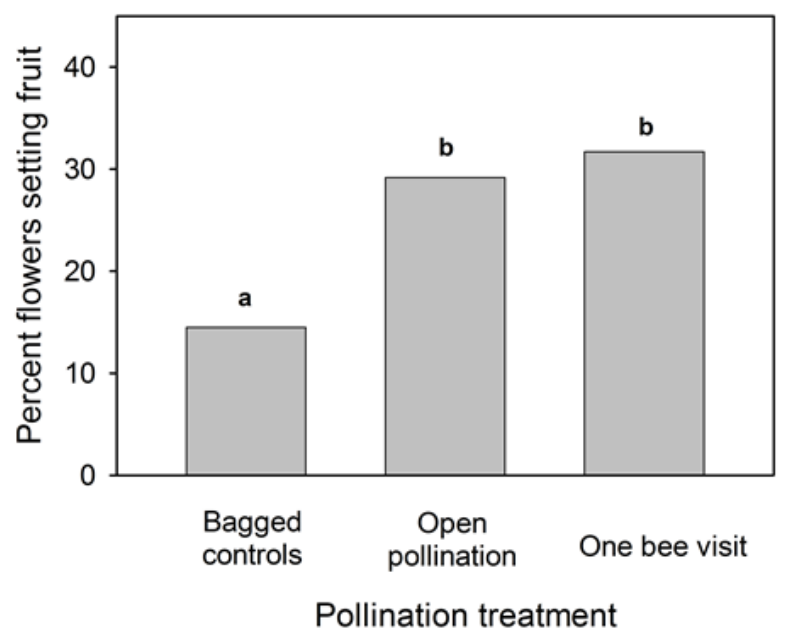

FIGURE 3. Percent of flowers setting fruit in closed and bagged flowers, flowers open to all visitors, and flowers visited by a single honeybee forager. Letters indicate percentages that are significantly different from each other at the $P=0.05$ level.

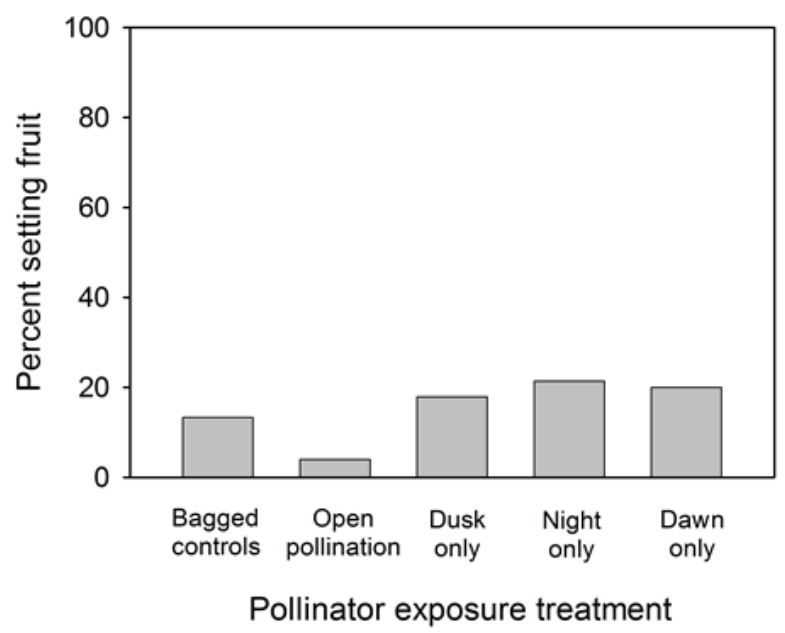

Figure 4. Percent of flowers setting fruit under different bagging treatments. There were no significant differences in the percentages.

geitonogamous selfing, or outcrossing. For example, progeny from autogamous pollination resulted in progeny with lower resistance to herbivory than progeny from open pollination in the D. wrightii congener Datura stramonium (Bello-Bedoy and Núñez-Farfán 2010). In D. wrightii, autonomously selfed fruit do not make as many seeds as fruit pollinated by hawkmoths (Bronstein et al. 2009). Thus, although we had no evidence that the percent of flowers setting fruit in the experiment differed, it is possible that different pollinators produced fruit with different numbers of seeds or with seeds of differing quality, both of which may have important consequences for the overall fitness of the maternal plant. Investigating these possibilities lay beyond the scope of the present study, but are important to consider in future work.

Honeybees are pollen thieves in other systems. For example, Hargreaves et al. (2010) found that the addition of A. mellifera scutellata hives reduced the anther pollen loads and the amount of pollen receipt on stigmas of Aloe maculata (Asphodelaceae) in eastern South Africa. Moreover, honeybee additions reduced the pollen loads found on sunbirds, the primary pollinator in that system. Vaughton (I996) similarly found that Grevillea barklyana (Proteaceae) plants caged with A. mellifera set $50 \%$ fewer fruit than did plants caged with both bees and birds. In $D$. wrightii, reductions of pollen mass on anthers caused by honeybee visits prior to hawkmoth visitation could negatively affect the ability of $M$. sexta to remove or deposit pollen during the night. In terms of effects on behavior, hawkmoths might not avoid flowers visited by honeybees because honeybees cannot reach $D$. wrightii nectar unless they resort to nectar larceny while hawkmoths don't actively seek pollen.

There are other examples of organisms that generally decrease plant fitness but can have neutral or positive effects in the absence of pollinators that move conspecific pollen to stigmas. Florivores reduce plant fitness either directly through consumption of gametes, or indirectly by affecting pollinator activity (McCall \& Irwin 2006; González-Browne 2016) but there are also cases where florivores have a negligible effect on fitness components (Pohl 2006; McCall 2007), Another relationship is nectar robbery, wherein an organism acquires nectar without pollination. Nectar robbing often results in decreased female plant fitness (González-Browne et al. 2016) but neutral (Rojas-Nossa et al. 2016; Heiling et al. 2018) or positive effects on plant fitness are also possible (see Irwin et al. 2010 and Singh et al. 2014).

Honeybees can act as pollen thieves or pollinators both in and out of their native range, having significant impacts on plant populations across large regions. Honeybees often pollinate plants outside of the bees' native range, sometimes having a net positive effect on fitness (Aslan et al. 2016; Russo 2016). In general, per-visit pollinator efficiency rates for honeybees may be lower than those for some native pollinators (Hung et al. 2018), but the sheer number of visits by honeybees could result in a net positive effect on plant fitness. Alternatively, frequent visitation could have negative effects on fruit set. For example, Young (1988) found that increased visits by beetles increased fruit set up to a point, but decreased fruit set thereafter in Dieffenbachia longispatha (Araceae). In another example, Willmot and Búrquez (1996) found that up to three hawkmoth visits to Merremia palmeri (Convolvulaceae) led to an increase in fruit set, but thereafter more visits decreased fruit set. These negative effects of increased pollinator visitation could be caused by pollen dislodgement, pollen tube crowding, or damage to primary reproductive tissues (Young and Young 1992).

The positive effects of honeybee visits on plant fitness may be especially important when there are low numbers of native pollinators. For example, the typical bird pollinators of the Hawaiian tree species Metrosideros polymorpha have become rare, but honeybee foragers have become effective pollinators in the system (Junker et al. 2010). Habitat fragmentation can negatively affect native pollinator numbers, but honeybees can compensate for these losses in some species in Argentina (Aizen \& Feinsinger 1994). In general, D. wrightii's native hawkmoth pollinators are apparently not in decline, but their numbers vary from year to year and there may be years of very low M. sexta activity (Alarcón et al. 2010). In these low years A. mellifera foragers could 
compensate for reduced hawkmoth services through the number of their visits and their morning pollination activity which doesn't typically occur with hawkmoths.

Other plants have similar bimodal or dual pollination systems, some of which include hawkmoth pollinators. In the genus Tritonioposis there are instances of species that are pollinated by both sunbirds and nectivorous insects (Manning and Goldblatt 2005). In Clarkia breweri, both nocturnal hawkmoths and diurnal bees are frequent floral visitors and carry $C$. breweri pollen, suggesting that the plant could benefit from both types of insect (Miller et al. 20I4). In Polemonium brandegei, researchers found that both hummingbirds and hawkmoths visited flowers in high numbers and might select for the variation in herkogamy seen across native plant populations (Kulbaba and Worley 2008).

Honeybees are frequent pollinators of both agricultural and native plants and often have similar per-visit pollinator efficiencies as other pollinators. Their pollination activities may or may not result in a net fitness gain in natural populations, depending on the identity of the total pollinator fauna, the degree to which a plant may be specialized for certain types of flowers, and the abundance of native pollinators, among other factors (Hung et al. 2018). It is possible that their role in maintaining native plant populations may increase with continued habitat fragmentation, urbanization, and losses in insect diversity, especially if native pollinators are negatively impacted by continued human activity. To understand how these changes will affect our natural areas, we will need more studies that include monitoring of both honeybee and native pollinators, experiments establishing pollinator efficiencies of both honeybees and coexisting pollinators, and studies, like this one, that manipulate both honeybee and primary pollinator visitation rates in a field setting.

\section{ACKNOWLEDGEMENTS}

We would like to thank Denison University and the Battelle Foundation for funding E.T., S.J., and M.E. for three summers of research. A.C.M. thanks the Denison University Biology department and the Department of Ecology and Evolutionary Biology at the University of Arizona for their space, support, and time during the writing of this manuscript. Two anonymous reviewers helped to improve this manuscript. We also thank Dr. Lyn Loveless and Emily McCall for fieldwork help.

\section{REFERENCES}

Aizen MA, Feinsinger P (1994) Forest fragmentation, pollination, and plant reproduction in a Chaco Dry Forest, Argentina. Ecology 75:330-35I.

Alarcón R, Riffell JA, Davidowitz G, Hildebrand JG, Bronstein JL (2010) Sex-dependent variation in the floral preferences of the hawkmoth Manduca sexta. Animal Behaviour 80:289-296.

Barker JL, Bronstein JL (2016) Temporal structure in cooperative interactions: what does the timing of exploitation tell us about its cost? PLOS Biology I4:eI00237I.

Bates D, Mächler M, Bolker B, Walker S (2015) Fitting linear mixed-effects models using lme4. Journal of Statistical Software 67 [online] URL: http://www.jstatsoft.org/v67/i0I/ (accessed 29 June 2018).
Bello-Bedoy R, Núñez-Farfán J (2010) Cost of inbreeding to resistance to herbivores in Datura stramonium. Annals of Botany 105:747-753.

Bronstein JL, Huxman T, Horvath B, Farabee M, Davidowitz G (2009) Reproductive biology of Datura wrightii: the benefits of a herbivorous pollinator. Annals of Botany I03:I435-I443.

Fox J, Weisberg S (20II). An $\{R\}$ Companion to Applied Regression, Second Edition. Sage, Thousand Oaks, CA.

González-Browne C, Murúa MM, Navarro L, Medel R (2016) Does plant origin influence the fitness impact of flower damage? A metaanalysis. PLOS ONE II:eOI46437.

Hargreaves AL, Harder LD, Johnson SD (2009) Consumptive emasculation: the ecological and evolutionary consequences of pollen theft. Biological Reviews 84:259-276.

Hargreaves AL, Harder LD, Johnson SD (2010) Native pollen thieves reduce the reproductive success of a hermaphroditic plant, Aloe maculata. Ecology 91:1693-1703.

Hargreaves AL, Harder LD, Johnson SD (2012) Floral traits mediate the vulnerability of aloes to pollen theft and inefficient pollination by bees. Annals of Botany 109:76I-772.

Heiling JM, Ledbetter TA, Richman SK, Ellison HK, Bronstein JL, Irwin RE (2018) Why are some plant - nectar robber interactions commensalisms? Oikos [online] URL: http://doi.wiley.com/ I0.1 III/oik.05440 (accessed 23 June 2018).

Hung K-LJ, Kingston JM, Albrecht M, Holway DA, Kohn JR (2018) The worldwide importance of honey bees as pollinators in natural habitats. Proc. R. Soc. B 285:20172I40.

Inouye DW (1980) The terminology of floral larceny. Ecology 6I:I25I-I253.

Irwin RE, Bronstein JL, Manson JS, Richardson L (20I0) Nectar robbing: ecological and evolutionary perspectives. Annual Review of Ecology, Evolution, and Systematics 4I:27I-292.

Junker RR, Bleil R, Daehler CC, Blüthgen N (2010) Intra-floral resource partitioning between endemic and invasive flower visitors: consequences for pollinator effectiveness. Ecological Entomology 35:760-767.

Kearney TH, Peebles RH, Howell HT, McClintock E (1960) Arizona Flora, Second edition, University of California Press, Berkeley.

Kulbaba MW, Worley AC (2008) Floral design in Polemonium brangegei (Polemoniaceae): genetic and phenotypic variation under hawkmoth and hummingbird pollination. International Journal of Plant Sciences 169:509-522.

Manning JC, Goldblatt P (2005) Radiation of pollination systems in the Cape genus Tritoniopsis (Iridaceae: Crocoideae) and the development of bimodal pollination strategies. International Journal of Plant Sciences I66:459-474.

McCall AC (2007) Leaf damage and gender but not flower damage affect female fitness in Nemophila menziesii (Hydrophyllaceae). American Journal of Botany 94:445-450.

McCall AC, Irwin RE (2006) Florivory: the intersection of pollination and herbivory. Ecology Letters 9:I35I-I365.

Miller TJ, Raguso RA, May KA (20I4) Novel adaptation to hawkmoth pollinators in Clarkia reduces efficiency, not attraction of diurnal visitors. Annals of Botany II3:317-329.

Pohl N, Carvallo G, Botto-Mahan C, Medel R (2006) Nonadditive effects of flower damage and hummingbird pollination on the fecundity of Mimulus luteus. Oecologia I49:648-655.

Rojas-Nossa SV, Sánchez JM, Navarro L (2016) Effects of nectar robbing on male and female reproductive success of a pollinatordependent plant. Annals of Botany I I7:29I-297. 
Russo L (2016) Positive and negative impacts of non-native bee species around the world. Insects 7:69.

Singh VK, Barman C, Tandon R (20I4) Nectar robbing positively influences the reproductive success of Tecomella undulata (Bignoniaceae). PLoS ONE 9 [online] URL: https://www.ncbi. nlm.nih.gov/pmc/articles/PMC4I0382I/ (accessed 23 June 2018).

Solís-Montero L, Vergara CH, Vallejo-Marín M (2015) High incidence of pollen theft in natural populations of a buzzpollinated plant. Arthropod-Plant Interactions 9:599-6II.

Thorp RW (2000) The collection of pollen by bees. Plant Systematics and Evolution 222:2I I-223.

Vaughton G (1996) Pollination disruption by European honeybees in the Australian bird-pollinated shrub Grevillea barklyana (Protaceae). Plant Systematics and Evolution 200:89-I00.
Wester P, Johnson SD (2017) Importance of birds versus insects as pollinators of the African shrub Syncolostemon densiflorus (Lamiaceae). Botanical Journal of the Linnean Society I85:225239.

Willmott AP, Búrquez A (1996) The pollination of Merremia palmeri (Convolvulaceae): can hawk moths be trusted? American Journal of Botany 83:1050-1056.

Young H (1988) Differential importance of beetle species pollinating Diffenbachia lonispatha (Araceae). Ecology 69:832844.

Young H, Young TP (1992) Alternative outcomes of natural and experimental high pollen loads. Ecology 73:639-647. 